\title{
Jarisch Herxheimer Reaction in an Adolescent with Secondary Syphilis: A Case Report
}

\author{
Jain $\mathbf{S}^{1, \star}$, Mohapatra $L^{2}$, Mundada $\mathbf{P}^{3}$, Raj $\mathbf{P}^{3}$ \\ ${ }^{1}$ Department of Skin and VD, National Institute of Medical Sciences and Research Hospital, Jaipur, Rajasthan, INDIA. \\ ${ }^{2}$ Department of Skin and VD, IMS \& SUM Hospital, Bhubaneswar, Odisha, INDIA. \\ ${ }^{3}$ Department of Pharmacy Practice, Institute of Pharmacy, NIMS University, Jaipur, Rajasthan, INDIA.
}

\begin{abstract}
The Jarisch-Herxheimer reaction is defined as a transient immunological reaction, classically seen in patients during antimicrobial treatment of syphilis. Clinically, it manifests within $24 \mathrm{~h}$ with short-term constitutional symptoms (fever, chills, headache, myalgia) and exacerbation of existing cutaneous lesions. Herein, we present a case of Jarisch-Herxheimer reaction in an adolescent.
\end{abstract}

Key words: Jarisch-Herxheimer reaction, Syphilis, Adolescent, Immunological reaction, Antimicrobial treatment.

\section{INTRODUCTION}

Jarisch, Herxheimer and Krause described this reaction at the turn of the century, but it was initially noted in the $15^{\text {th }}$ century when topical arsenic was first used to treat syphilis. ${ }^{1}$ The initial literary description was given by Adolf Jarisch (Austrian dermatologist) in 1895, when he noted exacerbation of lesions in roseolar syphilis patients after treatment with mercury. ${ }^{2}$ Subsequently, in 1902, Karl Herxheimer (German dermatologist) independently reported a similar phenomenon. ${ }^{3}$ The reaction, typically occurring 6-12 h after therapy for syphilis is initiated, consists of fever, rigor, malaise, diaphoresis and an exacerbation of pre-existing cutaneous lesions. ${ }^{4}$ We present here a case of JarischHerxheimer Reaction (JHR) in an adolescent.

\section{CASE REPORT}

A 17-year-old boy presented to the Department of Skin and VD at National Institute of Medical Sciences Hospital Jaipur, Rajasthan, India, with multiple asymptomatic elevated solid lesions over the inner thighs, scrotum, penis, palms and soles for 5 days. On examination, multiple discrete skin-colored papules and plaques were seen on the inner thighs, scrotum and penile skin. Multiple discrete hyper pigmented to slightly erythematous papules were seen on the palms and soles (Figure 1). The patient did not give any history of penile ulcers. Peri-anal and oral examination was unremarkable. The patient gave a history of single heterosexual contact in the 8 weeks prior to the eruption. On laboratory examination, the patient had positive venereal disease research laboratory (VDRL) in a dilution titer of $1: 64$. Based on clinical and laboratory findings, a diagnosis of secondary syphilis was made. The patient was prescribed injection benzathine penicillin 2.4 million units deep intramuscular on buttocks after sensitivity testing at around $1 \mathrm{pm}$. Patient presented to the emergency department at around $7 \mathrm{pm}$ with fever and myalgia and on examination we observed the appearance of new lesions bilaterally over the forearms, which were erythematous and slightly painful. (Figures 2 and 3) Patient was febrile with a temperature of $101^{\circ} \mathrm{F}$. The patient refused a biopsy testing. Therefore, based on the history of penicillin injection within 24 $h$ along with clinical correlation, a diagnosis of JHR was made and the patient was started
DOI: 10.5530/ijopp.14.3.43

Address for correspondence: Dr. Sonal Jain,

Department of Skin and VD, National Institute of Medical Sciences and Research Hospital, NIMS University, Jaipur, Rajasthan, INDIA. Phone no: +91-8209907747 Email Id: sonalreachesout@ gmail.com

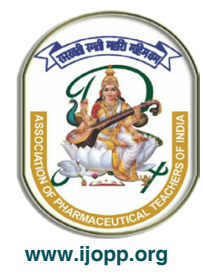




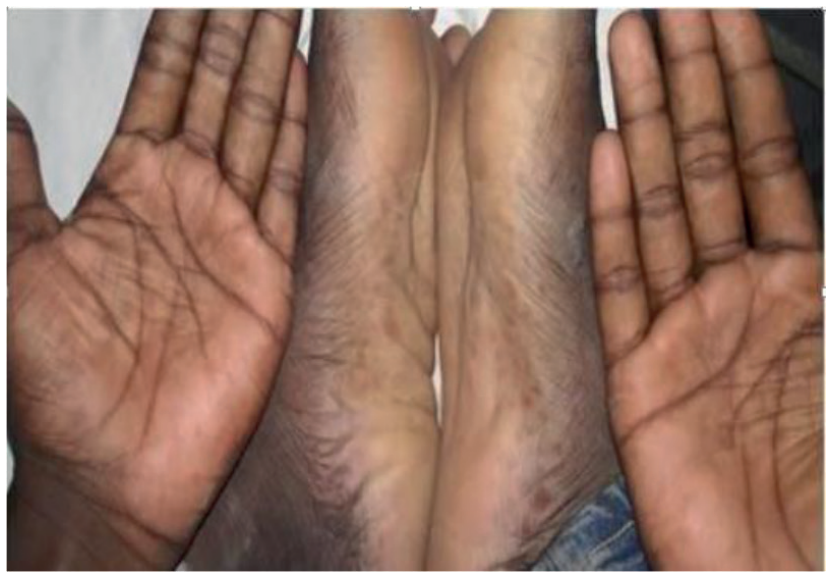

Figure 1: Multiple discrete hyperpigmented to slightly erythematous papules over palms and soles.

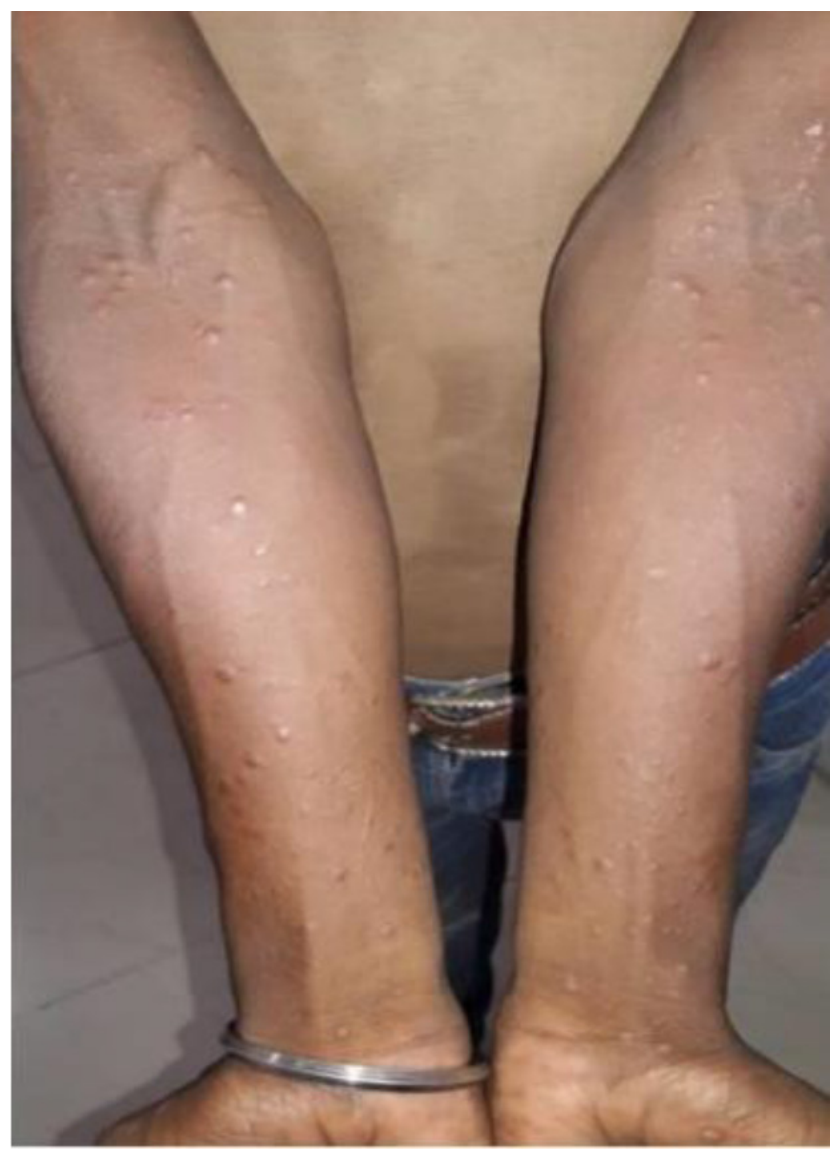

Figure 2: Multiple discrete erythematous papules and plaques over bilateral forearms post- penicillin injection.

on prednisolone $20 \mathrm{mg}$ for 7 days. There was complete clearance of lesions within 7 days.

This study was conducted ethically in accordance with the Declaration of Helsinki and the patient provided written informed consent for using clinical images and other information.

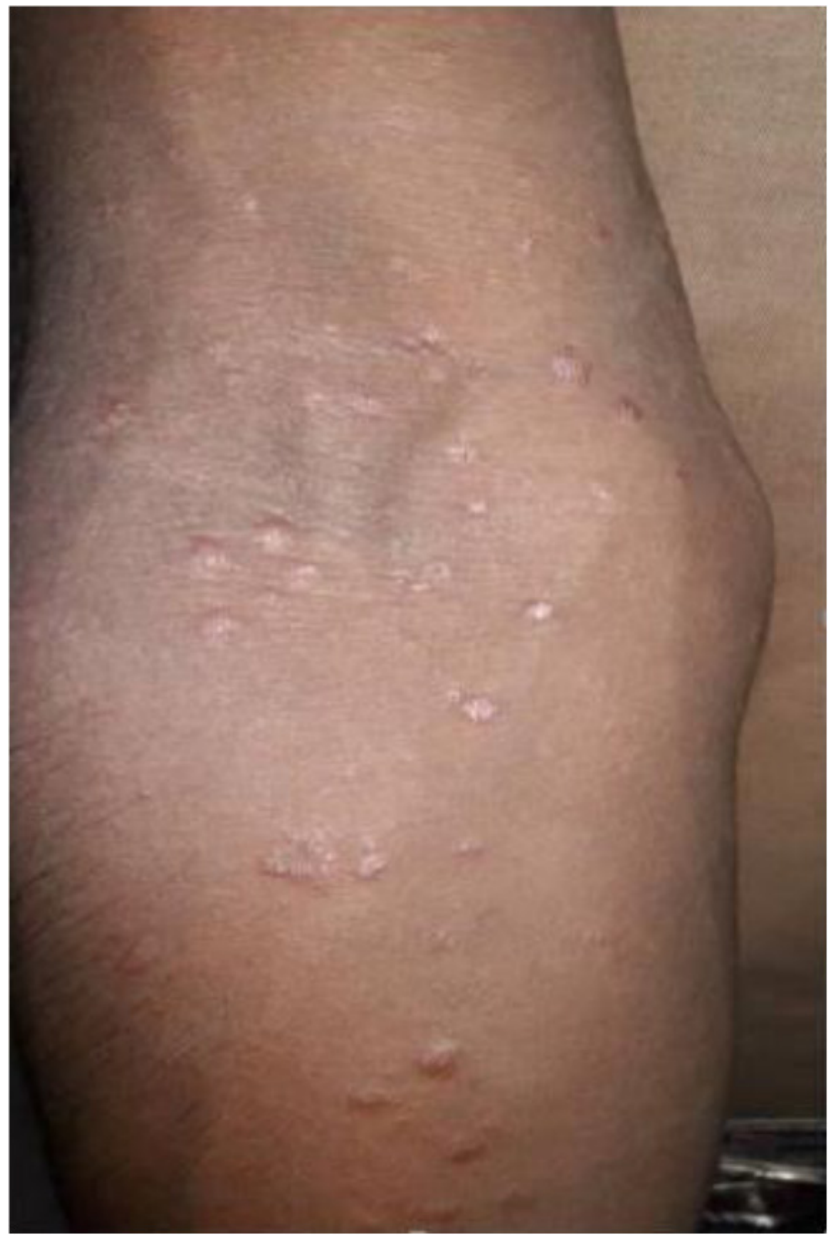

Figure 3: Multiple erythematous papules and plaques over right ante-cubital fossa plaques.

\section{DISCUSSION}

The JHR is defined as a transient immunological reaction, classically seen in patients during antimicrobial treatment for syphilis. It manifests within $24 \mathrm{~h}$ with shortterm constitutional symptoms (fever, chills, headache, myalgia) and exacerbation of existing cutaneous lesions. ${ }^{2}$ The terms "Herxheimer reaction", "Herxheimer effect", "therapeutic shock," and informally "Herx" are now used synonymously. ${ }^{5}$ The reaction is known to occur in seronegative primary syphilis (55\%), seropositive primary syphilis (95\%) and secondary syphilis $(95 \%) .{ }^{6} \mathrm{It}$ usually does not occur in latent syphilis. It is observed very rare in late syphilis, except in patients with general paresis of insane where it can occur in $75 \%$ of patients. ${ }^{6}$ On rare occasions, patients with neurosyphilis may experience seizures monoplegia, or hemiplegia. ${ }^{4}$ Another possibly dangerous outcome, although rare, is inflammation of the aorta or coronary Ostia in patients with cardiovascular involvement. ${ }^{4,7}$ This is a systemic febrile reaction occurring in about $60 \%$ of patients treated with penicillin for syphilis. ${ }^{7}$ Reactions similar to the JHR may occur in other infections. (Table 1) 
Table 1: Infections associated with JHR.

A. Well-documented
Syphilis
Louse-borne relapsing fever leptospirosis
Tick-borne relapsing fever
Lyme disease

Table 2: Depicting difference between JHR due to penicillin and penicillin hypersensitivity reaction.

\begin{tabular}{|c|c|c|}
\hline Features & $\begin{array}{l}\text { Jarisch-Herxheimer } \\
\text { reaction }\end{array}$ & $\begin{array}{l}\text { Penicillin } \\
\text { hypersensitivity } \\
\text { reaction }\end{array}$ \\
\hline $\begin{array}{l}\text { Onset of } \\
\text { reaction }\end{array}$ & Within 2-8 h & $\begin{array}{l}\text { Within few } \\
\text { minutes }\end{array}$ \\
\hline Symptoms & $\begin{array}{l}\text { Triad-fluctuation in body } \\
\text { temperature, flare and } \\
\text { physiological } \\
\text { changes }\end{array}$ & Urticaria/wheals \\
\hline $\begin{array}{l}\text { Laboratory } \\
\text { findings }\end{array}$ & $\begin{array}{c}\text { Not specific } \\
\text { (Polymorphonuclear } \\
\text { leukocytosis, } \\
\text { lymphopenia, raised ESR) }\end{array}$ & Eosinophilia \\
\hline Re-occurrence & Does not recur & $\begin{array}{l}\text { Reoccurs on } \\
\text { subsequent } \\
\text { administration }\end{array}$ \\
\hline $\begin{array}{c}\text { Specific } \\
\text { antibodies to } \\
\text { penicillin }\end{array}$ & Negative & Positive \\
\hline Treatment & $\begin{array}{l}\text { Self-resolving, } \\
\text { symptomatic } \\
\text { treatment }\end{array}$ & Stop Penicillin \\
\hline
\end{tabular}

Herxheimer postulated that the liberation of an endotoxin from degenerating treponemes following treatment of syphilis was the underlying mechanism. These products react with the "sensitized" syphilitic tissues and cause aggravation of lesions. ${ }^{8}$ There is transient elevation of pyogenic cytokines, such as TNF- $\alpha$ (first to rise), IL-6 (rises at the onset of symptoms) and IL-8. JHR is a self-resolving condition that can be managed symptomatically. JHR can also be confused with penicillin allergy (Table 2). Complete bed rest, fluids and antipyretics such as aspirin or acetaminophen are adequate for mild cases (early syphilis) associated with constitutional symptoms, whereas desensitization is required when beta-lactam hypersensitivity is confirmed and beta-lactam antibiotics are the treatment of choice. Oral and intravenous protocols for beta-lactams desensitization have been published starting from very low doses that are usually every 15 min until the full therapeutic dose is achieved. ${ }^{9}$

\section{CONCLUSION}

Clinicians should not confuse the JHR with a penicillin allergy as this is the drug of choice.

\section{CONFLICT OF INTEREST}

The authors declare that there is no conflict of interest.

\section{Declaration of Patient Consent}

The authors certify that they have obtained all appropriate patient consent forms. In the form, the patient has given consent for clinical images and other information to be reported in the journal. The patients understands that name and initials will not be published and due efforts will be made to conceal patient identity.

\section{ABBREVIATIONS}

JHR: Jarisch-Herxheimer Reaction; VDRL: venereal disease research laboratory.

\section{REFERENCES}

1. The Jarisch-Herxheimer reaction. Lancet. 1977;1:340-1.

2. Jarisch A. Therapeutische Versuchebei Syphilis. Wien Med Woch. 1895;45:720e1.

3. Herxheimer $\mathrm{K}$, Martin $\mathrm{H}$. Uber eine bei Syphilitische vorkommende Quecksilerber reaktion. Deutsch Med Wschr 1902;28:50.

4. Berkow R. Sexually transmitted diseases, in the Merck Manual. Rahway, NJ, Merck Research Laboratories. 1992;127:223.

5. Belum GR, Belum VR, Arudra SKC, Reddy BSN. The Jarisch-Herxheimer reaction: Revisited. Travel Med Infect Dis. 2013;11(4):231-7.

6. Aronson IK, Soltani K. The enigma of the pathogenesis of the JarischHerxheimer reaction. Br J Vener Dis. 1976;52(5):313.

7. Sparling PF. Syphilis: Cecil Textbook of Medicine, $18^{\text {th }}$ edition. Philadelphia, $\mathrm{Pa}$, WB Saunders. 1988;1713-22.

8. Negussie Y, Remick DG, DeForge LE, Kunkel SL, Eynon A, Griffin GE. Detection of plasma tumor necrosis factor, interleukin 6 and 8 during the Jarisch-Herxheimer Reaction of relapsing fever. J Exp Med. 1992;175(5):1207-12.

9. Solensky R. Drug desensitization. Immunol Allergy Clin North Am. 2004;24(3):425-43. 